\title{
CONSTELAÇÃO SISTÊMICA FAMILIAR VOLTADA AO PODER JUDICIÁRIO NA TÉCNICA DE MEDIAÇÃO JUDICIAL DOS PROCESSOS DE FAMÍLIA
}

\author{
SYSTEMIC FAMILY CONSTELLATION FOCUSED ON THE JUDICIARY IN THE \\ TECHNIQUE OF JUDICIAL MEDIATION OF FAMILY PROCESSES
}

\author{
CONSTELACIÓN SISTÉMICA FAMILIAR VOLVER AL PODER JUDICIAL EM LA \\ TÉCNICA DE MEDIACIÓN JUDICIAL DE LOS PROCESSOS DE FAMILIA
}

\author{
MARCELO LEANDRo PEREIRA LOPES \\ https://orcid.org/0000-0003-4043-3348 / http://lattes.cnpq.br/6764192599101350 / marcelolpl1@hotmail.com \\ Universidade de Fortaleza - UNIFOR. \\ Fortaleza, CE, Brasil.
}

VIVIANE MOURA DA COSTA

https://orcid.org/0000-0003-2501-6538 / http://lattes.cnpq.br/9495511866015659 / viviani_moura@hotmail.com Escola Hellinger Schule / Faculdade Innovare - São Paulo.

São Paulo, SP, Brasil.

\begin{abstract}
RESUMO
A Constelação Sistêmica Familiar é um método psicoterapêutico que foi desenvolvido pelo terapeuta e filósofo alemão Anton Suibert Hellinger (1980). O método sistêmico visa superação, reconhecimento e possível alteração dos emaranhamentos que surgem no sistema familiar, com base nas leis intituladas "Ordens do Amor". A aplicação da Constelação Familiar junto ao poder judiciário proporciona às partes envolvidas na lide outra forma de lidar com os problemas. Questiona-se, com isto, quais os benefícios desencadeados pela aplicação da Constelação Sistêmica Familiar na mediação judicial dos conflitos, principalmente, nas causas que versam sobre o Direito de Família. Tendo como objetivo principal analisar se a aplicação do método sistêmico pode contribuir para a pacificação dos conflitos familiares. A metodologia está centrada numa pesquisa bibliográfica e exploratória. Quanto a abordagem de análise das informações, será qualitativa.
\end{abstract}

Palavras-chave: Constelação; Direito; Família; Mediação Familiar.

\section{ABSTRACT}

The Family Systemic Constellation is a psychotherapeutic method developed by the German philosopher Anton Suibert Hellinger (1980). The systemic method aims at overcoming, recognizing and possibly changing the entanglements that arise in the family system, based on the laws called "Orders of Love". The application of the Family Constellation to the judiciary gives the parties involved in the dispute another way of dealing with the problems. This question is what the benefits of the application of the Family System Constellation in the judicial mediation of conflicts, especially in cases related to Family Law. Its main objective is to analyze whether the application of the systemic method can contribute to the pacification of family conflicts. The methodology is centered on a bibliographical research, exploratory and the approach to analysis of information will be qualitative.

Keywords: Constellation; Family; Judicial Mediation; Right.

\section{RESUMEN}

La Constelación Sistémica Familiar es un método psicoterapéutico que fue desarrollado por el terapeuta y filósofo alemán Anton Suibert Hellinger (1980). El método sistémico busca superar, reconocer y posible alteración de los 
enredos que surgen en el sistema familiar, con base en las leyes tituladas "Órdenes del Amor". La aplicación de la Constelación Familiar ante el poder judicial proporciona a las partes involucradas en el frente otra forma de lidiar con los problemas. Se cuestiona, con esto, cuáles son los beneficios desencadenados por la aplicación de la Constelación Sistémica Familiar en la mediación judicial de los conflictos, principalmente, en las causas que versan sobre el Derecho de Familia. Con el objetivo principal de analizar si la aplicación del método sistémico puede contribuir a la pacificación de los conflictos familiares. La metodología se centra en una investigación bibliográfica y exploratoria. En cuanto al enfoque de análisis de las informaciones, será cualitativa.

Palabras clave: Constelación; La Ley; La Familia; Mediación Familiar.

\section{SUMÁRIO}

INTRODUÇAO; 1 CONSTELAÇÃO SISTÊMICA FAMILIAR; 1.1 A família à luz da Teoria Sistêmica de Bert Hellinger; 1.2 Os campos morfogenéticos; 1.30 conflito sob a ótica sistêmica de Bert Hellinger; 2 MEDIAÇÃO SOB O ENFOQUE SISTÊMICO; 2.1 Mediação e acesso à justiça; 2.2 Mediação judicial como ferramenta à aplicação da visão sistêmica da Constelação Familiar; CONCLUSÃO; REFERÊNCIAS.

\section{INTRODUÇÃO}

A Constelação Sistêmica Familiar é um método psicoterapêutico, de fundo filosófico, desenvolvido pelo filósofo Anton Suitbert Hellinger (1980). A técnica visa a superação de crises pessoais e familiares na vida. A mesma poderá ser desenvolvida em grupo ou na terapia individual, utilizando-se de bonecos para solucionar os emaranhados, ou seja, problemas de relacionamentos. Essas soluções se darão com base nas leis que regem o sistema familiar intituladas "Ordens do Amor".

0 método caracteriza-se sob o enfoque fenomenológico, no qual se considera a existência de um campo de força denominado campo morfogenético ou campos organizativos. Tal campo atua entre o participante da constelação e os membros de seu sistema familiar, quando da aplicação do método em grupo ou na terapia individual. ${ }^{2}$

O Poder Judiciário, nos últimos tempos, passa por uma mudança de paradigmas no trato dos conflitos, tanto no sentido de transformação do modelo adversarial em consensual ${ }^{3}$ quanto na forma de recepção dos meios autocompositivos, em especial, o método da mediação nas ações de família.

\footnotetext{
${ }^{1}$ HELLINGER, B. Ordens do Amor: um guia para o trabalho com constelações familiares. Tradução Newton de Araújo Queiroz. Revisão técnica Eloisa Giancoli Tironi, TsuyukoJinno-Spelter. São Paulo: Cultrix, 2007a. p. 17.

2 SHELDRAKE, R. Morphic Resonance. Disponível em: <https://www.sheldrake.org/research/morphicresonance>. Acesso em: 17 out. 2017. Não paginado.

3 OLIVEIRA, L.D.; SPENGLER, F.M. O Fórum múltiplas portas como política de acesso à justiça e à pacificação social. Curitiba: Multideia, 2013.
} 
Diante do exposto, tem-se como objeto do presente artigo a Constelação Sistêmica Familiar voltada ao Poder Judiciário na técnica de Mediação Judicial dos Processos de Família. Nessa perspectiva, buscou-se reunir informações com o propósito de responder ao seguinte problema de pesquisa: Quais os benefícios desencadeados na realização da Constelação Familiar na solução dos conflitos judiciais, em especial, nas causas que versam sobre o Direito de Família?

Destarte, tendo em vista a crise no Poder Judiciário atual no que tange o aumento das demandas e a solução dos conflitos, num Judiciário não desenvolvido para tanto, questiona-se: Será eficaz a aplicação do método da Constelação Familiar na solução dos litígios das ações de família?

Espera-se, portanto, que os resultados obtidos forneçam embasamento científico para a análise da aplicação do método fenomenológico da Constelação Familiar no Poder Judiciário, principalmente, na técnica da Mediação Judicial. Tendo em vista as dificuldades existentes na pacificação e não apenas na mera solução dos conflitos que chegam aos tribunais do nosso país.

Para o desenvolvimento do presente trabalho e com o objetivo de analisar se a aplicação do método fenomenológico pode contribuir para a pacificação dos litígios familiares, foi utilizada a pesquisa bibliográfica, tendo como base estudos já organizados e sistematizados apresentados por meio de livros, leis e artigos científicos. Para tanto, foi desenvolvida uma abordagem qualitativa e exploratória, buscando analisar a possibilidade de adequação do método sistêmico da Constelação Familiar junto ao meio autocompositivo da Mediação Judicial.

\section{CONSTELAÇÃO SISTÊMICA FAMILIAR}

Neste item, analisa-se a noção de família por meio da Teoria Sistêmica de Bert Hellinger. Depois, conceitua-se os campos morfogenéticos até atingirmos a natureza e a compreensão do conflito sob a perspectiva do citado autor.

\subsection{A família à luz da Teoria Sistêmica de Bert Hellinger}

Sob a ótica das experiências e vivências com o método da Constelação Familiar, o presente artigo se limita a exposição geral da técnica e apresenta a visão sistêmica de Bert Hellinger, além do seu significado quanto ao surgimento do conflito no sistema familiar. A explicação do método foi realizada com a utilização de poucos acervos bibliográficos que dissertam sobre o tema, tendo em vista a quantidade reduzida de obras que reproduzem fielmente os ensinamentos do filósofo supracitado. 
A expressão constelação é originária da palavra alemã Familienaufstellung, que significa “Colocação Familiar”. No Brasil, assim como em todos os países da América, a palavra foi traduzida para Family Constellation /Constelaciones Familiares/ Constelação Familiar. Trata-se de um método psicoterapêutico que foi desenvolvido pelo terapeuta e filósofo alemão Anton Suitbert Hellinger, conhecido hodiernamente por Bert Hellinger. ${ }^{4}$

Os estudos das experiências do médico J. L. Moreno com a técnica do teatro de improviso, conhecido como psicodrama, no qual eram representados conflitos psíquicos e relacionais, auxiliaram no desenvolvimento do método das Constelações Sistêmicas Familiares por Bert Hellinger. ${ }^{5}$

Imperioso destacar, ainda de acordo com os ensinamentos do filósofo Jakob Schneider, as contribuições da terapeuta familiar Virginia Satir com as suas "esculturas" representativas do cenário familiar em sua totalidade. As imagens reproduziam e contemplavam várias gerações da família.

Hellinger, ${ }^{6}$ na qualidade de membro de uma ordem missionária de católicos, estudou, viveu e trabalhou durante 16 anos entre o povo Zulus na África do Sul, conduzindo diversas escolas de nível superior.

A posteriori, tornou-se psicanalista e, com o auxílio das abordagens da Dinâmica de grupo, das artes plásticas de Virginia Satir, da Terapia Primária, da Análise Transacional e dos métodos hipnoterapêuticos, desenvolveu sua própria Terapia Sistêmica e Familiar ${ }^{7}$ denominada Constelação Sistêmica Familiar (CSF).

O método visa a superação, o reconhecimento e a possível alteração dos emaranhamentos que surgem no sistema familiar, com base nas leis que regem as relações familiares intituladas pelo filósofo de "Ordens do amor", que serão analisadas no tópico pertinente à temática.

\footnotetext{
${ }^{4}$ SCHUBERT, R. Bert Hellinger: breve biografia. 2011. Disponível em: <http://aconstelacaofamiliar.blogspot.com.br/2011/07/bert-hellinger-breve biografia.html>. Acesso em: 17 out. 2017.

5 SCHNEIDER, J. R. A prática das Constelações Familiares: bases e procedimentos. Patos de Minas: Atman, 2007.

${ }^{6}$ HELLINGER, B. Ordens do Amor: um guia para o trabalho com constelações familiares. Tradução Newton de Araújo Queiroz. Revisão técnica Eloisa Giancoli Tironi, TsuyukoJinno-Spelter. São Paulo: Cultrix, 2007a. 7 Ibidem.
} 
CONSTELAÇ̃̃O SISTÊMICA FAMILIAR VOLTADA AO PODER JUDICIÁRIO NA TÉCNICA DE MEDIAÇÃO JUDICIAL DOS PROCESSOS DE FAMÍLIA

MARCELo LEANDRo PEREIRA LoPES VIVIANE MOURA DA COSTA

A Constelação Familiar é tida como uma técnica sistêmica, a aplicação do método “[...] não considera a pessoa como um indivíduo único, solto no mundo, ela considera o indivíduo como pertencente a um sistema do qual ele veio, o sistema familiar" ${ }^{8}$.

A família, para Hellinger, ${ }^{9}$ vai muito além do que nós geralmente definimos e consideramos. Para enfatizar esta definição, o autor utiliza a expressão sistema familiar. Com base na sua visão sistêmica o:

Sistema aqui significa uma comunidade de pessoas unidas pelo destino, através de várias gerações, cujos membros podem ser envolvidos no destino de outros membros. Reconhece-se a amplitude do sistema pela amplitude dos destinos que provocam tais envolvimentos. ${ }^{10}$

Desse sistema formado por uma comunidade de pessoas unidas pelo destino pertencem ao sistema familiar, em geral, as seguintes pessoas:

O filho e seus irmãos ou meio-irmãos, inclusive os falecidos e natimortos. Este é o nível inferior; Depois no nível imediatamente superior, vêm os pais e seus irmãos ou meio-irmãos, inclusive os prematuramente falecidos e os natimortos;A seguir, mais um nível acima, incluem-se os avós e, mais raramente algum irmão ou meioirmão dos mesmos. Isso, porém é raro; Às vezes inclui-se, também raramente, algum bisavô; Entre os anteriores citados, estão especialmente importantes as pessoas que tiveram um destino funesto ou foram lesados por membros do sistema - por exemplo, em assuntos de herança - ou que foram excluídas, dadas a terceiros, desprezadas ou esquecidas; Seguem-se então - e muitas vezes são estas as pessoas mais importantes - todos os que cederam lugar a outros nesse sistema, mesmo que não sejam parentes. É o caso, por exemplo, de algum cônjuge ou noivo anterior dos pais ou dos avós, mesmo que já falecido;Também fazem parte do sistema o pai ou a mãe dos meio-irmãos; Pertencem-lhe ainda aquelas pessoas de cuja desvantagem ou prejuízo alguém do sistema foi beneficiado, por exemplo, recebendo alguma herança por motivo de sua morte prematura ou por terem sido deserdadas. - Incluem-se, além disso, todos os que colaboraram para a vantagem de alguém no sistema, por exemplo, como empregados, e que depois sofreram prejuízo ou injustiça. É preciso, entretanto, que se trate de um grande prejuízo e de uma grande injustiça. - Não pertencem ao sistema, nesse sentido, tios ou tias agregados pelo casamento, bem como primos e primas. ${ }^{11}$

8 ERVOLINO, D. 0 que é constelação familiar. 2012. p. 1. Disponível em: <http://www.portaleducacao.com.br/psicologia/artigos/11859/o-que-e-constelacaofamiliar\#ixzz462l0d75i>. Acesso em: 17 out. 2017.

${ }_{9}^{9}$ HELLINGER, B. Ordens do Amor: um guia para o trabalho com constelações familiares. Tradução Newton de Araújo Queiroz. Revisão técnica Eloisa Giancoli Tironi, TsuyukoJinno-Spelter. São Paulo: Cultrix, 2007a

10 Ibidem.

11 Ibidem. 
CONSTELACCÃO SISTÊMICA FAMILIAR VOLTADA AO PODER JUDICIÁRIO NA TÉCCICA DE MEDIAÇÃO JUDICIAL DOS PROCESSOS DE FAMÍLIA

MARCELo LeANDRo Pereira Lopes VIVIANE MOURA DA COSTA

Hellinger $^{12}$ esclarece ainda que a proximidade física de pessoas consideradas importantes no seio familiar como, por exemplo, alguma avó ou tia, não tem relevância quando no caso de emaranhamentos. Os emaranhamentos, expressão importante utilizada na Constelação, são "envolvimentos no destino alheio. O original Verstrickungé também ocasionalmente traduzido por envolvimento ou enredamento". ${ }^{13}$

\subsection{Os campos morfogenéticos}

O método fenomenológico da Constelação Sistêmica Familiar é explicado pela Teoria dos Campos Morfogenéticos. A ideia da existência dos campos foi desenvolvida pelo biólogo Rupert Sheldrake com base na biologia e na análise do comportamento dos animais. ${ }^{14}$

Os campos morfogenéticos, consoante os ensinamentos de Sheldrake, ${ }^{15}$ são considerados a espécie mais ampla de campos, intitulados campos mórficos. A palavra mórfico vem do vocábulo grego morphe, que significa "forma". ${ }^{16}$ Os campos morfogenéticos são "campos de forma, campos padrões ou estruturas de ordem". ${ }^{17}$

A partir da década de 1920 foi confirmada a existência dos campos morfogenéticos. Porém, não há indicativos da sua origem. ${ }^{18}$ Os biólogos que, à época, estudavam a evolução dos vegetais e dos animais se convenceram de que "além dos genes, é necessário que haja no organismo em desenvolvimento alguns campos organizativos, chamados campos morfogenéticos". ${ }^{19}$

Os campos magnéticos da física representam por analogia as ideias de Rupert. O biólogo explica que "se você cortar um imã em várias partes, cada parte será ainda um imã completo,

\footnotetext{
12 HELLINGER, B. Ordens do Amor: um guia para o trabalho com constelações familiares. Tradução Newton de Araújo Queiroz. Revisão técnica Eloisa Giancoli Tironi, TsuyukoJinno-Spelter. São Paulo: Cultrix, 2007a

13 SCHNEIDER, J. R.A prática das Constelações Familiares: bases e procedimentos. Patos de Minas: Atman, 2007. p. 12.

${ }^{14}$ SHELDRAKE, R. A sensação de estar sendo observado e outros aspectos da mente expandida. São Paulo: Cultrix, 2004.

${ }^{15}$ Idibem.

${ }^{16}$ Idibem.

17 ROMANO, E. C. Bases Científicas das Constelações Familiares. 2015. p. 1. Disponível em: <http: //somostodosum.ig.com.br/clube/artigos.asp?id=44960 >. Acesso em: 17 de out. 2017.

${ }^{18}$ TRIPICCHIO, A. Ressonância Mórfica de Rupert Sheldrake. 2007. Disponível em: <http://webcache.googleusercontent.com/search?q=cache:c1ztZ2LwFrwJ:adalbertotr1.dominiotemporari o.com/doc/RessonanciaMorficadeRupertSheldrake. $d o c+\& c d=4 \& h l=p t-B R \& c t=c l n k \& g l=b r />$. Acesso em: 17 out.2017.

19 SHELDRAKE, R. A sensação de estar sendo observado e outros aspectos da mente expandida. São Paulo: Cultrix, 2004. p. 294.
} 
CONSTELAÇ̃̃O SISTÊMICA FAMILIAR VOLTADA AO PODER JUDICIÁRIO NA TÉCNICA DE MEDIAÇÃO JUDICIAL DOS PROCESSOS DE FAMÍLIA

MARCELo LEANDRo PEREIRA LOPES VIVIANE MOURA DA COSTA

dotado de um campo magnético completo". ${ }^{20}$ Porém, ao contrário dos campos magnéticos, os campos mórficos não envolvem transmissão de energia, mas sim de informação. ${ }^{21}$

Ademais, nas palavras biólogo "todos os campos mórficos têm certas propriedades em comum e todos contêm uma memória intrínseca fornecida por um processo denominado ressonância mórfica”.22

"Morphic ressonance is a process where by self-organising systems in herit a memory from previous similar systems" ${ }^{23}$ (Ressonância mórfica é um processo pelo qual os sistemas de auto-organização herdam uma memória de sistemas similares anteriores). Sheldrake ${ }^{24}$ afirma que:

Os campos mórficos de todas as espécies têm a sua história e contêm uma memória intrínseca dada pelo processo que chamo de ressonância mórfica. Essa ressonância se estabelece pela semelhança entre os padrões de atividade dos sistemas auto- organizadores. A ressonância mórfica se dá no espaço e também no tempo, do passado para o presente. Através da ressonância mórfica, cada indivíduo de uma espécie faz uso da memória coletiva da espécie e contribui para essa memória.

Tripicchio, ${ }^{25}$ no mesmo nível de raciocínio do biólogo, esclarece que:

A maneira pela qual os indivíduos do passado, [...] influencia os campos mórficos dos indivíduos atuais que thes correspondem, depende de um processo chamado ressonância mórfica, a influência do semelhante sobre o semelhante através do espaço e do tempo. A ressonância mórfica não diminui com a distância. Não envolve transferência de energia, mas de informação.

Os campos mórficos "contêm a memória coletiva da espécie". ${ }^{26}$ No sistema familiar, a citada memória traz os fatos ocorridos no passado da família. Essa memória provida de

${ }^{20}$ SHELDRAKE, R. A sensação de estar sendo observado e outros aspectos da mente expandida. São Paulo: Cultrix, 2004. p. 295.

21 ROMANO, E. C. Bases Científicas das Constelações Familiares. Disponível em: $<$ https: / / www. somostodosum.com.br/clube/artigos.asp?id=44960>. Acesso em: 17 out. 2017

22 SHELDRAKE, R. A sensação de estar sendo observado e outros aspectos da mente expandida. São Paulo: Cultrix, 2004. p. 29.

23 SHELDRAKE, R. [200-]. Morphic Resonance. Disponível em: $<$ http://www.sheldrake.org/research/morphic-resonance>. Acesso em: 17 out. 2017. Não paginado.

${ }^{24}$ SHELDRAKE, R. A sensação de estar sendo observado e outros aspectos da mente expandida. São Paulo: Cultrix, 2004, p. 296.

25 TRIPICCHIO, A. Ressonância Mórfica de Rupert Sheldrake. 2007. Disponível em: $<$ http://webcache.googleusercontent.com/search?q=cache:c1ztZ2LwFrwJ:adalbertotr1.dominiotemporari o.com/doc/RessonanciaMorficadeRupertSheldrake.doc+\&cd=4\&hl=pt-BR\&ct=clnk\&gl=br/>. Acesso em: 17 out. 2017.

26 SHELDRAKE, R. A sensação de estar sendo observado e outros aspectos da mente expandida. São Paulo: Cultrix, 2004. p. 297. 
CONSTELAÇ̃̃O SISTÊMICA FAMILIAR VOLTADA AO PODER JUDICIÁRIO NA TÉCNICA DE MEDIAÇÃO JUDICIAL DOS PROCESSOS DE FAMÍLIA

MARCELo LEANDRo PEREIRA LOPES VIVIANE MOURA DA COSTA

informação se manifesta no padrão de comportamento do indivíduo na instituição familiar, tal como a chamada herança comportamental ou, ainda, comportamento transferido de geração a geração. Nas palavras de Tripicchio: ${ }^{27}$

Quanto maior for a frequência com que um padrão de desenvolvimento é repetido, tanto maior será a probabilidade de que ele venha a ser novamente adotado. Os campos constituem os meios pelos quais os hábitos de cada espécie são formados, mantidos e herdados.

A memória coletiva é comparada àquilo que o psiquiatra Jung intitulou de inconsciente coletivo. Na definição de Jung: ${ }^{28}$

0 inconsciente coletivo é uma parte da psique que pode distinguir-se de um inconsciente pessoal pelo fato de que não deve sua existência à experiência pessoal, não sendo, portanto, uma aquisição pessoal. Enquanto o inconsciente pessoal é constituído essencialmente de conteúdos que já foram conscientes e no entanto desapareceram da consciência por terem sido esquecidos ou reprimidos, os conteúdos do inconsciente coletivo nunca estiveram na consciência e portanto não foram adquiridos individualmente, mas devem sua existência apenas à hereditariedade. Enquanto o inconsciente pessoal consiste em sua maior parte de complexos, o conteúdo do inconsciente coletivo é constituído essencialmente de arquétipos.

Jung $^{29}$ ressalta que o conceito de arquétipo é primordial para a ideia do inconsciente coletivo, definindo-o como formas da psique existentes em todo tempo e em todo lugar. Sobre os arquétipos $\operatorname{Saleh}^{30}$, com base nos ensinamentos do psiquiatra, argumenta que:

0 inconsciente coletivo é um reservatório de imagens, chamadas de arquétipos ou imagens primordiais, que cada pessoa herda de seus ancestrais. A pessoa não se lembra das imagens de forma consciente, porém, herda uma predisposição para reagir ao mundo de forma que seus ancestrais faziam.

$\mathrm{Na}$ aplicação do método da Constelação o inconsciente coletivo do sistema familiar se manifesta por meio dos sentimentos e sensações dos representantes que estão no campo,

27 TRIPICCHIO, A. Ressonância Mórfica de Rupert Sheldrake, 2007. Disponível em: <http://webcache.googleusercontent.com/search?q=cache:c1ztZ2LwFrwJ:adalbertotr1.dominiotemporari o.com/doc/RessonanciaMorficadeRupertSheldrake. $d o c+\& c d=4 \& h l=p t-B R \& c t=c \operatorname{lnk\& gl}=b r />$. Acesso em: 17 out. 2017. Não paginado.

28 JUNG, C. G. 1875-1961. Os arquétipos e o inconsciente coletivo. 2. ed. Rio de Janeiro: Vozes, 2002, p. 53.

${ }^{29}$ Idibem.

30 SALEH, A. M. 0 inconsciente coletivo - Márcio Cadurim. Disponível em: <https://grassetilly.wordpress.com/2014/06/19/o-inconsciente-coletivo-marciocadurim/>. Acesso em: 17 out. 2017. 
CONSTELACC̃̃O SISTÊMICA FAMILIAR VOLTADA AO PODER JUDICIÁRIO NA TÉCNICA DE MEDIAÇÃO JUDICIAL DOS PROCESSOS DE FAMÍLIA

independentemente de saber a história da pessoa que representam. Isso se dá pois no campo “[...] cada um dos representantes está em ressonância com todos”. ${ }^{31}$

Para a compreensão do método fenomenológico é essencial o reconhecimento da existência de um campo mental ou de uma mente ampliada, a qual Rupert nomeou "extended mind". ${ }^{32} 0$ biólogo considera os campos mentais uma espécie de campo mórfico e explica que "a mente expandida se projeta no ambiente por meio da atenção e da intenção e se liga a outros membros dos grupos sociais". ${ }^{33}$

\subsection{0 conflito sob a ótica sistêmica de Bert Hellinger}

O conflito é o desequilíbrio que surge a partir do desrespeito, confrontação e negligência de uma das Leis que regem o sistema familiar denominadas por Bert Hellinger de "Ordens do Amor" ${ }^{34}$. Estas leis estão orientadas pela consciência coletiva e foram batizadas pelo filósofo como: a lei do pertencimento, a lei da hierarquia e a lei do equilíbrio. De acordo com esse autor, a lei do pertencimento determina que todos têm o direito de pertencer e integrar o sistema familiar, independentemente do mal que tenha perpetrado a outro indivíduo.

Entrementes, o ente familiar que comete um ato condenável tanto pela família quanto pela sociedade, não tem o direito de ser excluído do núcleo no qual está habituado, uma vez que "[...] todas as tentativas de excluir uma pessoa ou de livrar-se dela são fadadas ao fracasso". ${ }^{35} 0$ ente perpetrador deve ser reconhecido e tomado com respeito, ainda que o comportamento intolerável seja suscetível à aplicação de penalidades impostas pela lei.

A alienação parental, caso frequente nas Varas de Família do nosso País, cometida pelo pai/pela mãe, enquadra-se precisamente nos ditos anteriores. Nesse sentido, Madaleno ${ }^{36}$ explica a lei do pertencimento com o seguinte caso:

31 HELLINGER, B. Ordens do Amor: um guia para o trabalho com constelações familiares. Tradução Newton de Araújo Queiroz. Revisão técnica Eloisa Giancoli Tironi, TsuyukoJinno-Spelter. São Paulo: Cultrix, 2007a. p. 17.

32 HELLINGER, B. Para que o amor dê certo. São Paulo: Cultrix, 2006.

33 SHELDRAKE, R. A sensação de estar sendo observado e outros aspectos da mente expandida. São Paulo: Cultrix, 2004. p. 297.

34 HELLINGER, B. Ordens do Amor: um guia para o trabalho com constelações familiares. Tradução Newton de Araújo Queiroz. Revisão técnica Eloisa Giancoli Tironi, TsuyukoJinno-Spelter. São Paulo: Cultrix, 2007a.

35 Ibidem. p. 17.

36 MADALENO, C. A Alienação Parental, suas consequiências e a busca de soluções à luz das Constelações Familiares e do Direito Sistêmico. 2015, p. 12. Disponível em: <http://www.carpesmadaleno.com.br/gerenciador/doc/ce3c93873e2f4ac433a5bdac5c8f5b7daaliena_C_e 
Como no caso de uma mulher de 36 anos, separada de um companheiro, pai de seu filho - que afirmava ter justificativas plausíveis para impedir o contato paterno filial, mesmo porque o genitor não se mostrava muito presente. Queixava-se de não ter sucesso na profissão, não tendo qualquer prazer no seu trabalho; possuía relacionamentos vazios, nunca se conectando realmente a um parceiro, parecia impedir que eles se aproximassem muito. Segundo sua afirmação, percebe que inconscientemente escolheu como pai de seu filho alguém que já dava sinais de não ser muito presente na vida da prole. Iniciou-se uma constelação individual que trouxe à tona que ela própria fora alienada de seu pai, de uma forma mais sutil - lembrou-se, durante a dinâmica, que sua mãe não proibia o convívio, mas sempre tecia muitos comentários ofensivos sobre seu pai, além de a convivência entre os dois ser permeada por brigas. 0 genitor da cliente nunca teve um lugar na família, sempre fora tratado como fraco e sem serventia, sendo veladamente excluído daquele sistema.

No caso referenciado, o sentimento de vingança concebido pelo pai/pela mãe é o único meio de compensar os danos, os abalos emocionais sofridos por um relacionamento frustrado. A partir desse sentimento, os pais se esquecem do dever de equilíbrio emocional em face do filho, que é tratado como um "boneco de elástico", uma vez que é tido como o centro das disputas.

A segunda lei, intitulada lei da hierarquia, prevê que a ordem que cada ente familiar ocupa na família deve ser tomada com respeito. ${ }^{37}$ Ou seja, os mais novos devem obediência aos mais velhos, tanto na relação pais/filho, irmão/irmão, avós/neto. Ademais, há que se destacar que se incluem também nessa lei os relacionamentos anteriores do pai/mãe, pois pertencem ao sistema familiar. Assim:

Outro exemplo clássico de desrespeito da ordem de chegada é quando ocorre a separação do casal e um dos dois casa-se novamente. Os novos companheiros, nova esposa ou esposo, entram para a família como segundos na ordem de chegada. Quando se observa que esses se comportam de forma a querer mandar em tudo e modificar muita coisa, falar mal dos ex-companheiros, isso traz muito desequilíbrio para o atual casal. Geralmente, os filhos, se existirem, não aceitam. A primeira esposa ou esposo, gostemos ou não, sempre farão parte da história daquela família e daquele relacionamento afetivo. Eles devem ser respeitados, independentemente do que aconteceu anteriormente. ${ }^{38}$

A última lei que rege as relações familiares, denominada lei do equilíbrio, equilíbrio entre dar e tomar, prevê que nos relacionamentos entre pai/mãe, pais/filhos, irmão/irmão,

oparentalsuasconsequ_unciaseabuscadesolu_C_les_aluzdasconstela_C_lesfamiliaresedodireitosist_umico.p df>. Acesso em: 5 out. 2017.

37 SCHNEIDER, J. R. A prática das Constelações Familiares: bases e procedimentos. Patos de Minas: Atman, 2007.

38 MARQUES. J.B. $2^{\circ}$ Lei do Amor: 0 equilíbrio entre dar e receber, 2016, p. 1. Disponível em: <http://www.jrmcoaching.com.br/blog/constelacao-familiar-2-lei-do-amor-o-equilibrio-entre-dar-ereceber/>. Acesso em: 5 out. 2017. 
CONSTELAÇ̃̃O SISTÊMICA FAMILIAR VOLTADA AO PODER JUDICIÁRIO NA TÉCNICA DE MEDIAÇÃO JUDICIAL DOS PROCESSOS DE FAMÍLIA

MARCELO LEANDRo PEREIRA LOPES VIVIANE MOURA DA COSTA

deve-se dar, trocar e receber de maneira proporcional. ${ }^{39} \mathrm{Na}$ relação em que não há igualdade de afeto, respeito, surge o desejo de compensar o que está ausente. Por exemplo:

No relacionamento entre um casal, também pode haver desequilíbrio no momento em que um dos parceiros se sente superior ao outro, preferindo todo o seu amor e, sem perceber, se recusando a receber. Ao longo do tempo, a maturidade vai ruindo por causa da dependência afetiva e emocional, em seu lugar, encontramos um parceiro infantilizado. 0 interesse pela relação diminui e ocorre a busca por novas distrações e vícios que, a princípio, deverão preencher o vazio que um dos parceiros sente, ou ainda, há a possibilidade de adoecimento pela impossibilidade de retribuir o muito que recebeu. ${ }^{40}$

Posto isso, a busca pelo equilíbrio ou ainda pela justiça que os indivíduos almejam em suas relações, diante do surgimento de algum conflito, terá efeitos contrários ao pretendido, “[...] pois a necessidade de justiça tem consequências totalmente diversas quando se trata de perdas e danos". ${ }^{41} \mathrm{O}$ filósofo assim esclarece com um exemplo, in verbis:

Quando alguém nos faz algum mal, planejamos vingança. Isto é, para compensar queremos causar um mal também a essa pessoa. Isso decorre da necessidade de compensação, portanto da necessidade de justiça. [...] Ao nos vingarmos, ultrapassamos a necessidade de compensação e justiça e causamos mais sofrimento e dano ao outro do que ele nos causou. Mas o outro também quer vingança e assim o conflito entre nós nunca tem fim. A justiça torna-se aqui um pretexto para a vingança. ${ }^{42}$

Dessa maneira, quando essas leis são desrespeitadas no sistema familiar surge no campo da família a necessidade de compensar a injustiça sofrida. Assim, como meio de equiponderar o desequilíbrio, as partes tomam o poder judiciário como ferramenta idônea para resolver o conflito.

Nada obstante, de forma desapercebida, os envolvidos no litígio não têm a compreensão de que a maioria dos conflitos que acontecem na instituição familiar podem estar relacionados a acontecimentos passados, que não foram resolvidos por algum parente da família de origem e que estão apenas se repetindo na entidade familiar atual. "Muitos dos nossos problemas têm raiz

\footnotetext{
39 SCHNEIDER, J. R. A prática das Constelações Familiares: bases e procedimentos. Patos de Minas: Atman, 2007.

40 MARQUES. J.B. $2^{\circ}$ Lei do Amor: 0 equilíbrio entre dar e receber. 2016. Disponível em: <http://www.jrmcoaching.com.br/blog/constelacao-familiar-2-lei-do-amor-o-equilibrio-entre-dar-ereceber/>. Acesso em: 5 out. 2017.

41 HELLINGER, B. Ordens do Amor: um guia para o trabalho com constelações familiares. Tradução Newton de Araújo Queiroz. Revisão técnica Eloisa Giancoli Tironi, TsuyukoJinno-Spelter. São Paulo: Cultrix, 2007a. p. 15.

42 HELLINGER, B. Paz e Conflito: uma resposta. São Paulo: Cultrix, 2007b. p. 61.
} 
no passado, justamente em nossa formação familiar, o que condiciona, inclusive, as nossas futuras tessituras afetivas". ${ }^{43}$

A Constelação Sistêmica Familiar é uma maneira de resolver os conflitos familiares sob o ponto de vista da abordagem sistêmica de Bert Hellinger, a qual considera a família como um sistema. A solução para o litígio surge quando as partes olham para o todo familiar e conseguem entender as dinâmicas que não são perceptíveis com a consciência individual.

\section{CONCLUSÃO}

Tendo em vista a crise no Poder Judiciário atual, percebe-se o quanto o acesso à justiça no que se refere ao aumento das demandas e a pacificação dos conflitos existentes, em um judiciário não desenvolvido para tanto, têm se tornado um estorvo para aqueles que o acionam e desejam pôr fim ao litígio em juízo.

Nessa perspectiva, o presente trabalho suscitou analisar se a aplicação da Constelação Sistêmica Familiar junto a Mediação judicial pode ser eficaz e pode contribuir para a pacificação dos conflitos que chagam ao Poder Judiciário, principalmente nas causas que versam sobre o Direito de Família.

No que tange os conflitos familiares, as partes litigantes buscam no Poder Judiciário, por meio da sentença do magistrado, a solução para as controvérsias e a segurança para que estas não sejam revividas. Isso acarreta uma desvalorização dos meios autocompositivos de solução de conflitos, dentre eles o instituto da Mediação, reputado, também, meio idôneo para solucionar as lides familiares.

A mediação, inserida no contexto judicial, após a entrada em vigor do novo Código de Processo Civil, ganhou expressa notabilidade, visto que passou a ser considerada um meio consensual de solução de conflito. No tocante a sua aplicação nas ações de família, a atenção é direcionada tão somente à atividade praticada dentro do Poder Judiciário. Isso não exclui, contudo, a prática da mediação extrajudicial.

Nessa perspectiva, notou-se no presente estudo que o entendimento do caráter interdisciplinar da mediação é essencial para a inovação do instituto. Assim, os mediadores que atuarão nos processos de família têm o dever de ampliar o conhecimento em busca da

${ }^{43}$ GAGLIANO, P. S. PAMPOLA FILHO, R. Novo Curso de Direito Civil. 6. ed. rev. e atual. de acordo com o novo CPC. São Paulo: Saraiva, 2016. p. 40. 
compreensão do Direito de Família sob o enfoque interdisciplinar, para entender que o conflito familiar não é único e, por esse motivo, pode vir a expressar-se em diferentes circunstâncias. Algumas vezes, por exemplo, manifesta-se sobre alimentos, depois se desloca para o regime de visitas, em outro momento, volta a se expressar sob forma de revisional de alimentos, fazendo assim com que o conflito familiar não finde e o Poder Judiciário não pacifique as controvérsias, mas tão somente as solucione.

Ademais, verificou-se que a Mediação judicial nas ações de família é um campo importante na atualidade para a aplicação da Constelação Sistêmica Familiar. Visto que o método fenomenológico, além de cooperar para o aprimoramento do Poder Judiciário e do meio de solução consensual de conflito supracitado, contribui para a harmonia e qualidade dos relacionamentos na instituição familiar. Vale ressaltar também que o litígio será encarado da melhor forma possível, com respeito e consideração à importância de cada membro do sistema familiar.

Trata-se, pois, de uma oportunidade de reconhecimento e ressignificação de cada ente da família no momento do conflito. Há, dessa forma, a partir de um olhar para o todo, a oportunidade de verificar o que está em desequilíbrio e quais comportamentos estão se repetindo na instituição familiar. Para que, ao final, as próprias partes litigantes reconheçam os emaranhamentos da família e assim assumam a responsabilidade por suas decisões no momento em que a imagem do conflito é apresentada pelo mediador.

\section{REFERÊNCIAS}

BANDEIRA, R. Constelação Familiar ajuda a humanizar práticas de conciliação no Judiciário, 2016. Disponível em: < http://www.cnj.jus.br/not\%C3\%ADcias/cnj/83766constela\%C3\%A7\%C3\%A3o-familiar-ajuda-humanizar-praticas-de-conciliacao-no-judiciario-2>. Acesso em: 17 out. 2017.

BARBOSA, A. A. Mediação Familiar Interdisciplinar. São Paulo: Atlas, 2015.

ERVOLINO, D. O que é constelação familiar, 2012. Disponível em:< http://www.portaleducacao.com.br/psicologia/artigos/11859/o-que-e-constelacaofamiliar\#ixzz462l0d75i >. Acesso em: 17 out. 2017.

GAGLIANO, P. S. PAMPOLA FILHO, R. Novo Curso de Direito Civil. 6. ed. rev. e atual. de acordo com o novo CPC. - São Paulo: Saraiva, 2016. 
GONÇALVES, F. AB.; TESCAROLLI, L. Leis Sistêmicas: a hierarquia, 2015. Disponível em:< http://www.carpesmadaleno.com.br/gerenciador/doc/09e7d4994e8515df65380e9e0a690b48leis sistemicas.pdf >. Acesso em: 5 out. 2017.

HELLINGER, B. Ordens do Amor: um guia para o trabalho com constelações familiares; tradução Newton de Araújo Queiroz; revisão técnica Eloisa Giancoli Tironi, TsuyukoJinno-Spelter. São Paulo: Cultrix, 2007.

HELLINGER, B. Para que o amor dê certo. São Paulo: Cultrix, 2006.

HELLINGER, B. Paz e Conflito: uma resposta. São Paulo: Cultrix, 2007.

JUNG, C. G., 1875-1961. Os arquétipos e o inconsciente coletivo. 2. ed. Rio de Janeiro: Vozes, 2002.

MADALENO, C. A Alienação Parental, suas consequiências e a busca de soluções à luz das Constelações Familiares e do Direito Sistêmico, 2015. Disponível em: < http: //www.carpesmadaleno.com.br/gerenciador/doc/ce3c93873e2f4ac4333a5bdac5c8f5b7daali ena_C_eoparentalsuasconsequ_unciaseabuscadesolu_C_les_aluzdasconstela_C_lesfamiliaresedodi reitosist_umico.pdf >. Acesso em: 5 out.2017.

MARQUES. J.B. $2^{\circ}$ Lei do Amor: 0 equilíbrio entre dar e receber, 2016. Disponível em:< http: //www.jrmcoaching.com.br/blog/constelacao-familiar-2-lei-do-amor-o-equilibrio-entredar-e-receber/>. Acesso em: 5 out. 2017.

NUNES, A. C. O. Manual de mediação: um guia prático para conciliadores. São Paulo: Editora Revista dos Tribunais, 2016.

OLIVEIRA, L.D.; SPENGLER, F.M. O Fórum múltiplas portas como política de acesso à justiça e à pacificação social. Curitiba: Multideia, 2013.

ROMANO, E. C. Bases Científicas das Constelações Familiares. Disponível em: $\leq$ https://www.somostodosum.com.br/clube/artigos.asp?id=44960> Acesso em: $1 \overline{7}$ out. 2017.

SALEH, A. M. O inconsciente coletivo- Márcio Cadurim. Disponível em: < https://grassetilly.wordpress.com/2014/06/19/o-inconsciente-coletivo-marciocadurim/ > Acesso em: 17 out. 2017.

SCHNEIDER, J. R. A prática das Constelações Familiares: bases e procedimentos. Patos de Minas: Atman, 2007.

SHELDRAKE, R. A sensação de estar sendo observado e outros aspectos da mente expandida. São Paulo: Cultrix, 2004.

SHELDRAKE, R. Morphic Resonance. Disponível em: < http://www.sheldrake.org/research/morphic-resonance > Acesso em: 17 out. 2017. 
SHUBERT, R. Bert Hellinger: breve biografia, 2011. Disponível em: <

http://aconstelacaofamiliar.blogspot.com.br/2011/07/bert-hellinger-breve biografia.html > Acesso em: 17 out. 2017.

STORCH, S. Direito Sistêmico: primeiras experiências com Constelações no Judiciário. Filosofia, pensamento e prática das Constelações Familiares. 4.ed. p. 56-62. out. 2015.

TRIPICCHIO, A. Ressonância Mórfica de Rupert Sheldrake, 2007. Disponível em:< http: // webcache.googleusercontent.com/search?q=cache:c1ztZ2LwFrwJ:adalbertotr1.dominiote mporario.com/doc/RessonanciaMorficadeRupertSheldrake. doc+\&cd=4\&hl=pt-BR\&ct=clnk\&gl=br/ > Acesso em: 17 out. 2017.

\section{COMO FAZER A REFERÊNCIA DO ARTIGO (ABNT):}

LOPES, Marcelo Leandro Pereira; COSTA, Viviane Moura da. Constelação sistêmica familiar voltada ao poder judiciário na técnica de mediação judicial dos processos de família. Revista Eletrônica do Curso de Direito da UFSM, Santa Maria, RS, v. 13, n. 3, p. 1190-1204, dez. 2018. ISSN 1981-3694. Disponível em: <

https://periodicos.ufsm.br/revistadireito/article/view/29591 >. Acesso em: dia mês. ano. doi:

http://dx.doi.org/10.5902/1981369429591 . 